\title{
Synthesis and antibacterial activity evaluation of novel rhodanine based amide derivatives
}

\author{
Mehrasa Tarahomi ${ }^{1}$, Robabeh Baharfar ${ }^{1 *}$ and Mojtaba Mohseni ${ }^{2}$ \\ ${ }^{1}$ Department of Chemistry, University of Mazandaran, Babolsar, Iran \\ ${ }^{2}$ Department of Microbiology, Faculty of Sciences, University of Mazandaran, Babolsar, Iran
}

\begin{abstract}
A novel series of rhodanine based amide derivatives have been prepared through multi-component reaction of rhodanine- $N$-acetic acid with aromatic aldehydes and alkyl isocyanides in the presence of aniline. The products were isolated in $85-95 \%$ yields by easy workup procedure. The synthesized compounds have also been evaluated for their antibacterial effects against four pathogenic bacteria, Escherichia coli, Pseudomonas aeruginosa, Staphylococcus aureus and Bacillus subtilis. On the basis of the obtained results, some compounds showed moderate growth inhibitory effect against all tested bacteria.
\end{abstract}

\section{Introduction}

A major dispute of modern chemistry is the plan of new chemical reaction successions that supply novel compounds in high yields. Multicomponent reactions (MCRs) [1] have become precious tools for the synthesis of highly functionalized organic molecules and pharmacologically important heterocyclic compounds because of their convergence, simplicity and synthetic efficiency, atom economy, and other suitable characteristics from the point of view of green chemistry [2]. MCRs are quicker and cheaper than conventional reactions, since they are performed by mixing compounds together in one pot, without separating any intermediate. Isocyanide-based MCRs (IMCRs) are especially important, because they are more diverse and flexible than other MCRs [3,4]. Amides are an incredibly vital group of organic compounds with a variety of functions. Some derivatives of amides reveal biological properties such as vermifuge [5], antihistamine [6], fungicide and antibacterial $[7,8]$. The conventional approach for the synthesis of amides is the reaction of carboxylic acids with amines at high temperature. Because of carboxylic acid's low activity, several procedures for their activation have been reported in the literature [9]. Negative aspects of these procedures consist of modest yields, byproducts, costly coupling reagents and difficulty in removal of surplus reagents. Consequently, the growth of a new and uncomplicated synthetic procedure for the preparation of amides has become an interesting challenge.

On the other hand, rhodanine (2-thioxothiazolidin-4-one) as a privileged scaffold is found in a variety of biologically active compounds especially with antiviral [10], antibacterial [11], antifungal [12], antitubercular [13], anticancer [14], anticonvulsant [15], and hypnotic activities [16]. Therefore, following our interest in isocyanide-based reactions and our studies towards the development of new directions for the synthesis of novel organic compounds with biological activities [17-19], we herein report the multi-component reaction of aromatic aldehydes 1 with aniline 2 , rhodanine- $N$-acetic acid 3 and isocyanides 4 in THF as a suitable procedure affording rhodanine-based amides 5 in good yields (Figure 1). The synthesized amides were also screened for their antibacterial activity by the disc diffusion method.

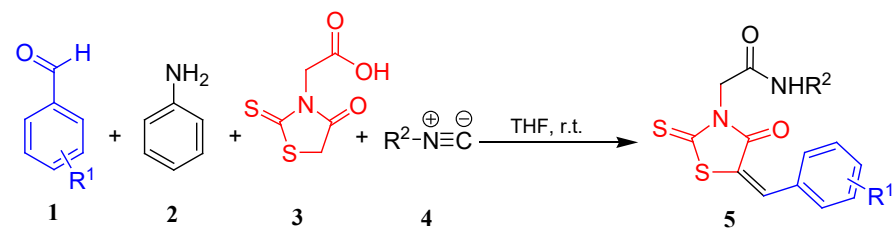

Figure 1. Multi-component reaction of rhodanine- $N$-acetic acid with aromatic aldehydes and alkyl isocyanides in the presence of aniline

\section{Experimental}

\section{General information}

All chemicals and reagents were purchased from Merck (Darmstadt, Germany) or Aldrich (Missouri, United States), and used without purification. Melting points were measured on an Electrothermal 9100 (Staffordshire, United Kingdom) apparatus. ${ }^{1} \mathrm{H}$ and ${ }^{13} \mathrm{C}$ NMR spectra were recorded on a Bruker DRX-400 AVANCE (Massachusetts, United States) spectrometer at 400.13 and $100.61 \mathrm{MHz}$, respectively. Chemical shifts are given in parts per million $(\delta)$ relative to internal tetramethylsilane standard and coupling constants $(\mathrm{J})$ are reported in hertz $(\mathrm{Hz})$. IR spectra were recorded on a Bruker Tensor 27 (Massachusetts, United States) spectrometer. Mass spectra were determined on a Finnigan-Matt 8430 (Waltham, United States) mass spectrometer operating at an ionization potential of $70 \mathrm{eV}$. Elemental analyses were carried on a Perkin-Elmer 2400II CHNS/O Elemental Analyzer (Massachusetts, United States).

\section{General procedure for the synthesis of compounds (5a-5j)}

A mixture of aromatic aldehydes $1(1 \mathrm{mmol})$, aniline $2(0.1 \mathrm{~mL}, 1$ mmol), rhodanine- $N$-acetic acid $3(0.2 \mathrm{~g}, 1 \mathrm{mmol})$ and alkyl isocyanides

*Correspondence to: Robabeh Baharfar, Department of Microbiology, Faculty of Sciences, University of Mazandaran, Babolsar, Iran, E-mail: baharfar@umz.ac.ir

Key words: rhodanine, alkyl isocyanides, aniline, multi-component reaction, antibacterial activity

Received: June 21, 2019; Accepted: July 08, 2019; Published: July 10, 2019 
$4(1 \mathrm{mmol})$ in $5.0 \mathrm{~mL}$ THF was stirred at $25^{\circ} \mathrm{C}$ for the definite time period. After completion of the reaction, checked by TLC, the solvent was removed under reduced pressure to provide desired product. The structures of products $5 \mathrm{a}-\mathrm{j}$ were determined on the basis of their elemental analysis, ${ }^{1} \mathrm{H}$ and ${ }^{13} \mathrm{C} \mathrm{NMR}$, IR and mass spectra.

\section{General procedure for evaluation of antibacterial activity}

The in vitro biocidal screening, antibacterial activities of the synthesized 2-(5-arylidene-4-oxo-2-thioxothiazolidin-3-yl)- $\mathrm{N}$ alkylacetamide derivatives $5 \mathrm{a}-\mathrm{j}$ was assayed using Kirby-Bauer disc diffusion method where a filter disc was impregnated with the compounds and placed on the surface of inoculated agar plates [20]. The synthesized compounds were dissolved into DMSO to achieve $20 \mathrm{mg}$ $\mathrm{mL}^{-1}$ solution then filter sterilised using a $0.22 \mathrm{~m}$ Ministart (Sartorius).

The antibacterial activity of the compounds was investigated against four bacterial species. Test organisms included Escherichi coli PTCC 1330, Pseudomonas aeruginosa PTCC 1074, Staphylococcus aureus ATCC 35923 and Bacillus subtilis PTCC 102 [21]. Late exponential phase of the bacteria was prepared by inoculating $1 \%(\mathrm{v} / \mathrm{v})$ of the cultures into the fresh Muller-Hinton broth (Merck) and incubating on an orbital shaker at $37^{\circ} \mathrm{C}$ and $100 \mathrm{rpm}$ overnight. Before using the cultures, they were standardized with a final cell density of approximately $10^{8}$ $\mathrm{cfu} \mathrm{mL}^{-1}$. Muller-Hinton agar (Merck) were prepared and inoculated from the standardized cultures of the test organisms then spread as uniformly as possible throughout the entire media. Sterile paper discs (6 mm diameter, Padtan, Iran) were impregnated with $20 \mu \mathrm{L}$ of the compound solution then allowed to dry. The impregnated disc was introduced on the upper layer of the seeded agar plate and incubated at $37^{\circ} \mathrm{C}$ for 24 hours. The antibacterial activities of the synthesized compounds were compared with known antibiotic gentamicin $(10 \mu \mathrm{g} /$ disc) and chloramphenicol ( $30 \mu \mathrm{g} / \mathrm{disc})$ as positive control and DMSO $(20 \mu \mathrm{L} /$ disc $)$ as negative control. Antibacterial activity was evaluated by measuring the diameter of inhibition zone $(\mathrm{mm})$ on the surface of plates and the results were reported as Mean \pm SD after three repeats.

\section{Results and discussion}

The desired product $5 \mathrm{a}$, confirmed by NMR and Mass spectra, was obtained in $90 \%$ yield (Figure 1) [22]. To illustrate the role of aniline, the reaction was checked in the absence of aniline. Interestingly, this reaction miscarried under reflux conditions, even after $24 \mathrm{~h}$, and starting materials were recovered. Additionally, the three-component reaction of benzilidenerhodanine- $N$-acetic acid $(1.0 \mathrm{mmol})$, benzaldehyde $(1.0$ $\mathrm{mmol})$ and tert-butyl isocyanide $(1.0 \mathrm{mmol})$ without aniline showed no progress in boiling THF even after long reaction time. Obviously, these results prove that aniline is a vital component for this reaction. Afterward the effect of solvent on this reaction was screened. The

Table 1. Optimization of reaction conditions for the synthesis of amide $5 \mathrm{a}^{\mathrm{a}}$

\begin{tabular}{|c|c|c|c|c|}
\hline Entry & Solvent & Temp/ ${ }^{\mathbf{C}}$ & Time/h & 13 \\
\hline 1 & THF & 25 & 90 \\
\hline 2 & $1,4-\mathrm{Dioxane}$ & 25 & 46 \\
\hline 3 & $\mathrm{CH}_{2} \mathrm{Cl}_{2}$ & 25 \\
\hline 4 & $\mathrm{EtOH}$ & 25 & 40 \\
\hline 5 & $\mathrm{H}_{2} \mathrm{O}$ & 25 & 48 \\
\hline 6 & $\mathrm{THF}$ & 25 & 48 \\
\hline
\end{tabular}

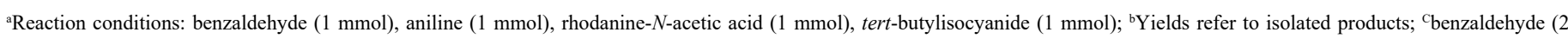
mmol)<smiles>O=C(O)CN1C(=O)CSC1=S</smiles>

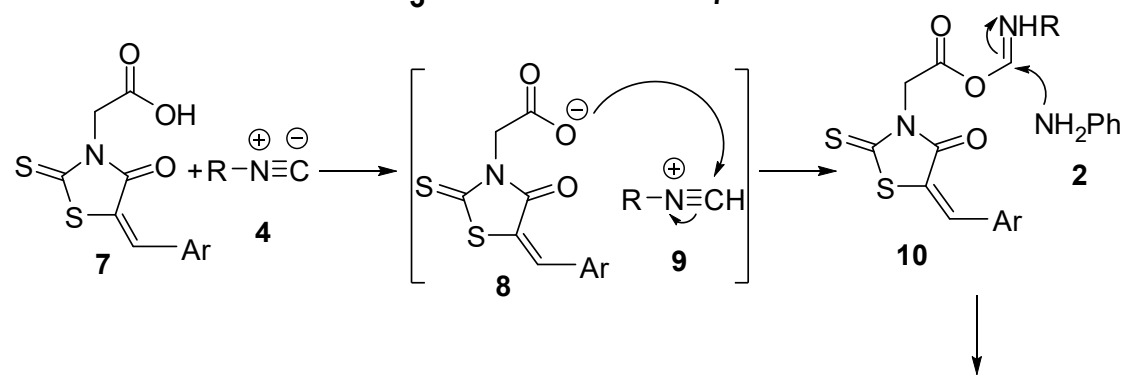<smiles>[R]NC(=O)CN1C(=O)/C(=C/[Al])SC1=S</smiles>

Figure 2. Proposed mechanism for the synthesis of rhodanine-based amides 5 
Table 2. Synthesis of rhodanine-based amides $5^{\mathrm{a}}$

\begin{tabular}{|c|c|c|c|c|c|c|}
\hline & $\mathbf{R}^{1}$ & $\mathbf{R}^{2}$ & Product & M.p. $\left({ }^{\circ} \mathrm{C}\right)$ & Time (h) & Yield (\%) \\
\hline 1 & $\mathrm{H}$ & tert-Butyl & & $225-227$ & 13 & 90 \\
\hline 2 & $4-\mathrm{NO}_{2}$ & tert-Butyl & & $250-252$ & 12 & 95 \\
\hline 3 & $4-\mathrm{CN}$ & Cyclohexyl & & $240-242$ & 12 & 95 \\
\hline 4 & $2-\mathrm{Cl}$ & tert-Butyl & & $215-218$ & 12.5 & 90 \\
\hline 5 & $4-\mathrm{Cl}$ & tert-Butyl & & $249-251$ & 12.5 & 95 \\
\hline 6 & $2-\mathrm{Br}$ & tert-Butyl & & $230-232$ & 12 & 90 \\
\hline 7 & $\mathrm{H}$ & Cyclohexyl & & $247-250$ & 13 & 90 \\
\hline 8 & 2-MeO & tert-Butyl & & $262-264$ & 14 & 85 \\
\hline 9 & 4-MeO & Cyclohexyl & & $250-252$ & 14 & 85 \\
\hline 10 & 2-furyl & tert-Butyl & & $205-208$ & 12 & 90 \\
\hline
\end{tabular}

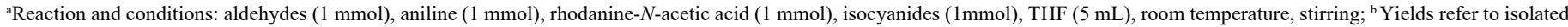
products. 
model reaction was carried out in different solvents including $\mathrm{CH}_{2} \mathrm{Cl}_{2}$, 1,4-dioxane, $\mathrm{EtOH}$ and $\mathrm{H}_{2} \mathrm{O}$ under similar conditions at ambient temperature (Table 1). As revealed in table 1, the maximum yield was observed in THF (Table 1). Therefore, the best result is achieved by the use of substrates in equimolar ratio in THF at room temperature.

To explore the substrate scope of this novel procedure, the condensation reactions of various aromatic and heteroaromatic aldehydes 1a-1i with rhodanine- $\mathrm{N}$-acetic acid 3 , and alkyl-isocyanides (tert-butyl isocyanide 4a and cyclohexylisocyanide $4 \mathrm{~b}$ ) in the presence of aniline 2 were studied in THF at room temperature. Under optimum reaction conditions, a novel series of rhodanine based amides were synthesized, the results are listed in table 2. In all cases, aromatic aldehyde substituted with either electron-donating or electronwithdrawing groups underwent the reaction smoothly and gave desired products in excellent yields (85\%-95\%). The reaction products were isolated by simple workup procedure and did not need any further purification steps. As can be seen from table 2, the presence of electronwithdrawing substituents on the aromatic aldehyde accelerated the reaction rate, whereas electron-releasing substituent reduced the rate of reaction. However, the nature of the substituents did not affect the yield of the products.

The structure of rhodanine-based amides 5 was deduced from ${ }^{1} \mathrm{H}$ and ${ }^{13} \mathrm{C}$ NMR, IR and mass spectra as well as elemental analyses. The physical properties, MS data and elemental analysis results for these compounds are listed in table 2, and the spectral data are shown in table 2. For example, the mass spectrum of 5a displayed the molecular ion $\left(\mathrm{M}^{+}\right)$peak at $m / z 334$, which this consistent with the structure of compound. The ${ }^{1} \mathrm{H}$ NMR spectrum of 5 a showed two sharp signals at 1.22 and $4.39 \mathrm{ppm}$ for the tert-butyl and methylene groups, a multiplet at 7.52-7.59 ppm and a doublet at $7.66 \mathrm{ppm}$ corresponding to five aromatic protons, and two singlets at 7.81 and $8.16 \mathrm{ppm}$ for vinyl proton and $\mathrm{NH}$, respectively. The ${ }^{13} \mathrm{C}$ NMR spectrum of $5 \mathrm{a}$ demonstrated 12 signals in agreement with the anticipated structure.

Although a mechanism for the formation of product 5 has not yet been established experimentally, a possible explanation is anticipated in figure 2. First, the Knoevenagel condensation between aldehyde 1 and rhodanine- $N$-acetic acid 3 in the presence of aniline 2 generates benzilidenerhodanine- $N$-acetic acid 7. According to the well-established chemistry of the reaction of isocyanides with acids [23], it is sensible to suppose that protonation of the isocyanide 4 by the carboxylic acid 3. Then nucleophilic attack of carboxylate 8 to nitrilium 9 produces $O$-acyl-imine 10 which on quenching with aniline rearranges to intermediate 12 . Finally, removal of $N$-phenyl from this intermediate gives rhodanine-based amide 5 [24].

\section{Antibacterial activity}

The antibacterial activity of synthesized compounds $5 \mathrm{a}-5 \mathrm{j}$ was evaluated against gram positive (S. aureus and B. subtilis) and gram negative bacteria (E. coli and $P$. aeruginosa) by the disc diffusion method; the results are illustrated in table 3 . In addition, the finding towards inhibition of microorganisms was compared with that of positive controls, gentamicin and chloramphenicol, and DMSO as a negative control. As presented in the table 3, compounds 5a, 5e, $5 \mathrm{f}$ and $5 \mathrm{j}$ exhibited moderate growth inhibitory effect against all tested bacteria, whereas compound $5 \mathrm{i}$ showed no activity. Compounds $5 b, 5 \mathrm{c}$ and $5 \mathrm{~h}$ displayed good activity against Gram positive bacteria while these compounds remained inactive against two Gram-negative bacteria. Moreover, compound 5d showed good activity against all bacteria except $B$. subtilis. In general, the antibacterial activities of these
Table 3. Antibacterial activity of the compounds $5 \mathrm{a}-5 \mathrm{j}$ using Kirby-Bauer technique (zone of growth inhibition, $\mathrm{mm})^{\mathrm{a}}$

\begin{tabular}{|c|c|c|c|c|}
\hline Compound & E. coli/mm & $\begin{array}{c}\boldsymbol{P} \text { aeruginosa/ } \\
\mathbf{m m}\end{array}$ & S. aureus/mm & B. subtili/mm \\
\hline $5 \mathrm{a}$ & $8.5 \pm 0.7$ & $8.5 \pm 0.7$ & $12.5 \pm 0.7$ & $10.5 \pm 0.7$ \\
\hline $5 \mathrm{~b}$ & $\mathrm{NE}^{\mathrm{b}}$ & $\mathrm{NE}$ & $16.5 \pm 0.7$ & $10.5 \pm 0.7$ \\
\hline $5 \mathrm{c}$ & $\mathrm{NE}$ & $\mathrm{NE}$ & $12.5 \pm 0.7$ & $10.5 \pm 0.7$ \\
\hline $5 \mathrm{~d}$ & $10.5 \pm 0.7$ & $10.0 \pm 1.4$ & $15.5 \pm 0.7$ & $\mathrm{NE}$ \\
\hline $5 \mathrm{e}$ & $11.5 \pm 0.7$ & $11.0 \pm 0.0$ & $10.5 \pm 0.7$ & $12.5 \pm 0.7$ \\
\hline $5 \mathrm{f}$ & $10.0 \pm 1.4$ & $9.0 \pm 1.4$ & $14.5 \pm 0.7$ & $15.0 \pm 1.4$ \\
\hline $5 \mathrm{~g}$ & $10.0 \pm 1.4$ & $9.5 \pm 0.7$ & $12.5 \pm 0.7$ & $\mathrm{NE}$ \\
\hline $5 \mathrm{~h}$ & $\mathrm{NE}$ & $\mathrm{NE}$ & $15.5 \pm 0.7$ & $8.0 \pm 0.0$ \\
\hline $5 \mathrm{i}$ & $\mathrm{NE}$ & $\mathrm{NE}$ & $\mathrm{NE}$ & $\mathrm{NE}$ \\
\hline $5 \mathrm{j}$ & $9.5 \pm 0.7$ & $9.5 \pm 0.7$ & $12.5 \pm 0.7$ & $14.5 \pm 0.7$ \\
\hline $\begin{array}{c}\text { Gentamicin } \\
(10 \mu \mathrm{g} / \text { disc })\end{array}$ & $19.6 \pm 1.1$ & $15.6 \pm 0.5$ & $20.3 \pm 1.5$ & $26.0 \pm 1.7$ \\
\hline $\begin{array}{c}\text { Chloramphenicol } \\
(30 \mu \mathrm{g} / \text { disc })\end{array}$ & $20.7 \pm 1.5$ & $\mathrm{NE}$ & $21.7 \pm 0.6$ & $22.3 \pm 1.2$ \\
\hline
\end{tabular}

${ }^{\mathrm{a} C}$ Concentration of compounds $5 \mathrm{a}-5 \mathrm{j}: 20 \mathrm{mg} \mathrm{mL}^{-1}$; ${ }^{\mathrm{b}} \mathrm{No}$ effect

compounds tended to be more potent against Gram-positive species than Gram-negative bacteria, which can be related to the variation in their cell wall structure.

\section{Conclusions}

In summary, we have reported an efficient approach for the synthesis of rhodanine-based amides via multi-component reaction of aromatic aldehydes, rhodanine- $N$-acetic acid and alkyl isocyanides in the presence of aniline in THF at ambient temperature. The advantages of the present procedure include good functional group tolerance, high yields of products, simple operation, and absence of any tedious workup or purification. On the basis of the obtained results from antibacterial test, compounds $5 \mathrm{a}, 5 \mathrm{e}, 5 \mathrm{f}$ and $5 \mathrm{j}$ showed moderate growth inhibitory effect against all tested bacteria. Among compounds, 5b exhibited the most antibacterial activity against $S$. aureus.

\section{Acknowledgements}

We gratefully acknowledge financial support from the Research Council of Mazandaran University.

\section{Supplementary data}

Electronic Supplementary Material associated with this article can be found in the online version of this paper.

\section{References}

1. Baharfar R, Azimi R, Asdollahpour Z (2018) Efficient microwave-assisted diastereoselective synthesis of indole-based 4, 5-dihydrofurans via a one-pot, threecomponent reaction in water. Environmental chemistry letters 2018: 1-6.

2. Cioc RC, Ruijter E, Orru RV (2014) Multicomponent reactions: advanced tools for sustainable organic synthesis. Green Chemistry. 16: 2958-2975.

3. Akbarzadeh R, Amanpour T, Khavasi HR, Bazgir A (2014) Atom-economical isocyanide-based multicomponent synthesis of 2, 5-dioxopyrrolidines, spirobenzothiazinechromans and 1, 5-benzothiazepines. Tetrahedron 70: 169-175.

4. Giustiniano M, Pelliccia S, Novellino E, Tron GC (2018) Non-hydrolytic chemoselective cleavage of Ugi tertiary amides: A mild access to N-substituted $\alpha$-amino acid amides. Tetrahedron letters 59: 1196-1199.

5. Kaur G, Vadekeetil A, Harjai K, Singh V (2015) Synthesis of $\alpha$-acylamino-amidebis (indolyl) methane heterocycles by sequential one pot condensation-Ugi/Passerini reactions and their antimicrobial evaluation. Tetrahedron letters 56: 4445-4450.

6. Battaglia S, Boldrini E, Da Settimo F, Dondio G, La Motta C, et al. (1999) Indole amide derivatives: synthesis, structure-activity relationships and molecular modelling studies of a new series of histamine H1-receptor antagonists. European journal of medicinal chemistry 34: 93-105. 
7. Greger H, Zechner G, Hofer O, Hadacek F, Wurz G (1993) Sulphur-containing amides from Glycosmis species with different antifungal activity. Phytochemistry 34: 175-179.

8. Beck B, Hess S, Dömling A (2010) One-pot synthesis and biological evaluation of aspergillamides and analogues. Bioorganic \& medicinal chemistry letters 10: 1701-1715.

9. Al-Zoubi RM, Marion O, Hall DG (2008) Direct and waste-free amidations and cycloadditions by organocatalytic activation of carboxylic acids at room temperature. Angewandte Chemie International Edition 47: 2876-2879.

10. Talele TT, Arora P, Kulkarni SS, Patel MR, Singh S, et al. (2010) Structure-based virtual screening, synthesis and SAR of novel inhibitors of hepatitis C virus NS5B polymerase. Bioorganic \& medicinal chemistry 18: 4630-4638.

11. Miao J, Zheng C-J, Sun L-P, Song M-X, Xu L-L, Piao H-R (2013) Synthesis and potential antibacterial activity of new rhodanine-3-acetic acid derivatives. Medicinal Chemistry Research 22: 4125-4132.

12. Chauhan K, Sharma M, Singh P, Kumar V, Shukla PK, et al. (2012) Discovery of a new class of dithiocarbamates and rhodanine scaffolds as potent antifungal agents: synthesis, biology and molecular docking. MedChem Comm 3: 1104-1110.

13. Babaoglu K, Page MA, Jones VC, McNeil MR, Dong C, et al. (2003) Novel inhibitors of an emerging target in Mycobacterium tuberculosis; substituted thiazolidinones as inhibitors of dTDP-rhamnose synthesis. Bioorganic \& medicinal chemistry letters 13 3227-3230.

14. Min G, Lee S-K, Kim H-N, Han Y-M, Lee R-H, et al. (2013) Rhodanine-based PRL-3 inhibitors blocked the migration and invasion of metastatic cancer cells. Bioorganic \& medicinal chemistry letters (13): 3769-3774.

15. Dwivedi C, Gupta T, Parmar SS (1972) Substituted thiazolidones as anticonvulsants Journal of medicinal chemistry 15: 553-554.

16. Shafii N, Khoobi M, Amini M, Sakhteman A, Nadri H, et al. (2015) Synthesis and biological evaluation of 5-benzylidenerhodanine-3-acetic acid derivatives as $\mathrm{AChE}$ and 15-LOX inhibitors. Journal of enzyme inhibition and medicinal chemistry 30: 389-395.
17. Baharfar R, Shariati N (2014) Solvent-free Synthesis of Novel Benzothiazolesubstituted 4-Thiazolidinones Using Nano Silica-bonded 5-n-Propyl-octahydropyrimido [1, 2-a] azepinium Chloride as Catalyst. Australian Journal of Chemistry 67: 1646-1655.

18. Baharfar R, Asghari S, Rassi S, Mohseni M (2015) Synthesis and evaluation of novel isatin and 5-isatinylidenerhodanine-based furan derivatives as antibacterial agents. Research on Chemical Intermediates 41: 6975-6984.

19. Baharfar R, Azimi R, Barzegar S, Mohseni M (2015) Efficient Synthesis of RhodanineBased Amides via Passerini Reaction using Tetramethylguanidine-Functionalized Silica Nanoparticles as Reusable Catalyst. Journal of the Brazilian Chemical Society 26: 1396-1404.

20. Drago L, Mombelli B, Ciardo G, Vecchi ED, Gismondo M (1999) Effects of three different fish Oil7 formulations on Helicobacter pylori growth and viability: in vitro study. Journal of chemotherapy. 11: 207-210.

21. Ghaemy M, Aghakhani B, Taghavi M, Nasab SMA, Mohseni M (2013) Synthesis and characterization of new imidazole and fluorene-bisphenol based polyamides: Thermal, photophysical and antibacterial properties. Reactive and Functional Polymers 73: 555563

22. Baharfar R, Tarahomi M, Azimi R (2019) Efficient Multicomponent Synthesis of Novel Rhodanine Based Amide Derivatives. Organic Preparations and Procedures International. In press.

23. Malaquin S, Jida M, Gesquiere J-C, Deprez-Poulain R, Deprez B, et al. (2010) Ugi reaction for the synthesis of 4-aminopiperidine-4-carboxylic acid derivatives. Application to the synthesis of carfentanil and remifentanil. Tetrahedron Letters 51: 2983-2985.

24. Shaabani A, Soleimani E, Rezayan AH (2007) A novel approach for the synthesis of aryl amides. Tetrahedron letters 48: 6137-6141.

Copyright: (C2019 Tarahomi M. This is an open-access article distributed under the terms of the Creative Commons Attribution License, which permits unrestricted use, distribution, and reproduction in any medium, provided the original author and source are credited. 